\title{
Cats (Felis catus) Show no Avoidance of People who Behave Negatively to their Owner
}

\author{
Hitomi Chijiiwa $^{1,2}$, Saho Takagi ${ }^{1,2}$, Minori Arahori ${ }^{1,2}$, James R. Anderson $^{1}$, Kazuo Fujita ${ }^{1}$, \& \\ Hika Kuroshima ${ }^{1}$
}

${ }^{1}$ Department of Psychology, Graduate School of Letters, Kyoto University

${ }^{2}$ Japan Society for the Promotion of Science

*Corresponding author (Email: chijiiwa.hitomi.5m@kyoto-u.ac.jp)

Citation - Chijiiwa, H., Takagi, S., Arahori, M., Anderson, J. R., Fujita, K., \& Kuroshima, H. (2021). Cats (Felis catus) show no avoidance of people who behave negatively to their owner. Animal Behavior and Cognition, 8(1), 23-35. https://doi.org/10.26451/abc.08.01.03.2021

\begin{abstract}
Humans evaluate others based on interactions between third parties, even when those interactions are of no direct relevance to the observer. Such social evaluation is not limited to humans. We previously showed that dogs avoided a person who behaved negatively to their owner (Chijiiwa et al., 2015). Here, we explored whether domestic cats, another common companion animal, similarly evaluate humans based on third-party interactions. We used the same procedure that we used with dogs: cats watched as their owner first tried unsuccessfully to open a transparent container to take out an object, and then requested help from a person sitting nearby. In the Helper condition, this second person (helper) helped the owner to open the container, whereas in the Non-Helper condition the actor refused to help, turning away instead. A third, passive (neutral) person sat on the other side of the owner in both conditions. After the interaction, the actor and the neutral person each offered a piece of food to the cat, and we recorded which person the cat took food from. Cats completed four trials and showed neither a preference for the helper nor avoidance of the non-helper. We consider that cats might not possess the same social evaluation abilities as dogs, at least in this situation, because unlike the latter, they have not been selected to cooperate with humans. However, further work on cats' social evaluation capacities needs to consider ecological validity, notably with regard to the species' sociality.
\end{abstract}

Keywords - Cats, Social evaluation, Third-party interaction, Social cognition, Cat-human relationship, Domesticated animals

Humans evaluate other people based on not only direct interactions with them but also how they interact with third parties, even when those interactions are of no direct relevance to us. We tend to praise prosocial individuals and castigate antisocial individuals, in manifestations of what is generally referred to as our moral sense (Hamlin, 2013). Several studies have demonstrated that affective evaluation of thirdparty interactions might be present from infancy. For example, after witnessing an adult either helping or harming another adult, 3-year-old children were less likely to help the harmful adult than a third (neutral) adult (Vaish et al., 2010). Even much younger children respond differently when they witness helpful vs. harmful interactions: preverbal infants preferred agents (geometrical shapes or hand puppets) that behaved prosocially toward others (e.g., helped them to climb up a hill, or to open a box) rather than hindering (Hamlin et al., 2007, 2010; Hamlin \& Wynn, 2011).

Comparative psychologists studying nonhuman animals have shed light on possible evolutionary origins of such sensitivity to third-party interactions. Individuals belonging to various social species discriminate between antisocial and prosocial others, and behave toward them differentially (for a review: 
Abdai \& Miklósi, 2016). For example, in the case of mutualism involving cleaner fish (Labroides dimidiatus), eavesdropping client fish avoid cleaners who defect (feeding on the client's mucus) more than those who cooperate (removing the client's ectoparasites) (Bshary, 2002). Most studies of third-party interactions in nonhumans have involved exchanges of food (chimpanzees, Pan troglodytes: Herrmann et al., 2013; Russell et al., 2008; Subiaul et al., 2008, orangutans, Pongo pygmaeus: Herrmann et al., 2013, common marmosets, Callithrix jacchus : Kawai et al., 2014, domestic dogs, Canis familiaris: Kundey et al., 2011; Marshall-Pescini et al., 2011). Typically, the subject observes as a human (or conspecific) begs for food from two persons; one is prosocial and gives food to the beggar, but the other is antisocial and either withholds food or prevents the prosocial person from giving food to the beggar. Following the observation, subjects tend to show a preference for the prosocial person. Alone, however, these results cannot rule out the possibility that simple associative learning led to subjects choosing the person who was more likely to give them food.

To address this problem, and inspired by methods used with human infants (e.g., Hamlin et al., 2007, 2010), recent studies of nonhumans have presented scenarios consisting of simple moving shapes (animation) to bottlenose dolphins (Tursiops spp.) (Johnson et al., 2018), bonobos (Pan paniscus) (Krupenye \& Hare, 2018), and dogs (McAuliffe et al., 2019). These studies have produced variable results. In Johnson et al. (2018), dolphins watched a "prosocial" shape appear to help a "neutral" shape to move upward, whereas an "antisocial" shape hindered it by pushing it downward. Next, the three shapes appeared together on the screen, then the prosocial and antisocial shapes moved off-screen in opposite directions. When the neutral shape moved behind a central occluder on the screen, the dolphins' looking responses suggested that they expected the neutral shape to follow the prosocial one rather than the antisocial one. In contrast, after bonobos observed a neutral shape interacting with prosocial and antisocial shapes, the apes reached toward the antisocial character (Krupenye \& Hare, 2018). Dogs were no more likely to approach a 'helper' than a 'hinderer' although they explored the latter for longer (McAuliffe et al., 2019). Although the use of simple moving shapes might eliminate any association between an actor and food, there might be species differences in the perception or understanding of the abstract animated events.

In research with tufted capuchin monkeys (Sapajus apella), Anderson et al. (2013) used a liveaction scenario in which the third-party interactions depicted either helpfulness or refusal to help. Importantly, that study did not use food during the interaction, meaning that the monkeys could not evaluate the actors based on actor-food associations. The monkeys saw two actors sitting next to each other. One actor was always an 'attempter' who tried to open a container to get an object from inside. Following the attempter's request for help, the second actor helped (in Helper sessions) or refused to help (in Non-helper sessions) her to open the container. After observing the interaction, the monkey could choose to take food from either the attempter or the helper/non-helper; both actors offered identical food to the monkey. The authors reported that monkeys were significantly less likely to accept food from the actor who previously refused the request for help, but they showed no preference for the helper. It is noteworthy that they compared the preference between neutral vs helper or non-helper rather than directly comparing the preference for helpers versus non-helpers. Doing so makes it possible to distinguish between a positive or negative bias.

Drawing on the findings in capuchin monkeys (Anderson et al., 2013), Chijiiwa et al. (2015) investigated dogs' evaluation of people in a similar scenario involving help or refusal to help. Dogs watched their owner trying but failing to open a container to remove an object. The owner then requested help from one of two persons. One of them either helped (Helper) or refused to help by turning away (Non-helper), while the other person (neutral) simply remained passive throughout. After they saw this sequence of events, dogs were given the choice of approaching and taking food offered by either the helper/non-helper (depending on the condition) or the neutral person. Similar to the capuchin monkeys, dogs were less willing to accept food from the non-helper, but they showed no preference for the helper over neutral person. The results for both capuchin monkeys and dogs suggest a "negativity bias," also exhibited in young human infants (Hamlin et al., 2010; Vaish et al., 2010). Anderson et al. (2017) suggested that this bias might reflect negative affective states such as disliking, feeling subordinate, or 
distrust. Due to possible greater survival value for social animals, a negativity bias might have evolved earlier and more often than a positivity bias (Abdai \& Miklósi, 2016). There is ample evidence that human adults display a strong negativity bias (for reviews, Baumeister et al., 2001; Rozin \& Royzman, 2001). However, the underlying mechanisms and functions of negativity bias in human infants and nonhumans might not be the same as in adult humans.

Here, we investigated how domestic cats (Felis catus) react to third-party interactions between humans, as previously studied in dogs (Chijiiwa et al., 2015). Because of their high popularity and long history as companion animals for humans, cats are useful for assessing socio-cognitive traits that might be shared with humans, given the two species' shared environment, and exposure to many of the same social events. To our knowledge, there is only one study of social evaluation in domestic cats and which did not involve food sharing. Leete et al. (2020) tested whether cats discriminate between two unfamiliar people, who engaged in 'friendly' or 'aggressive' (threatening) interaction with cats, based on both direct experiences and third-party interactions. Cats were tested in dyads: one exposed to two types of interactions with the two individuals, and the other observed those interactions through a one-way mirror. Cats did not show any preference (based on latency to approach and duration of contact) between the two strangers in this set-up. In the present study, we investigated third-party social evaluation in cats based more closely on procedures used with monkeys (Anderson et al., 2013) and dogs (Chijiiwa et al., 2015).

Recent research has shown that cats have remarkable social cognitive abilities. For example, they can follow human pointing (Miklósi et al., 2005) and gazing cues (Pongrácz et al., 2018), and they can discriminate human emotional expressions (Galvan \& Vonk, 2016; Merola et al., 2015; Quaranta et al., 2020) and attentional states (Ito et al., 2016; Vitale \& Udell, 2019). Moreover, cats recognize their owners (voice: Saito \& Shinozuka, 2013; voice-face matching: Takagi et al., 2019), and form attachment-like bonds (Edwards et al., 2007; Vitale et al., 2019). Although cats possess some socio-cognitive capacities reported in dogs (but see Pongrácz \& Onofer, 2020), the two species have quite different domestication histories and ecological backgrounds. The ancestor of cats (Felis silvestris), like most other felids (excluding lions, Panthera leo (Stander, 1992) and cheetahs, Acinonyx jubatus (Caro et al., 1989)) are solitary hunters and strongly territorial, with minimal contact between individuals except for mating or litter rearing (Bradshaw, 2016; Macdonald et al., 2000). These properties might appear to make cats unlikely candidates for domestication in general (Driscoll, Macdonald et al., 2009). In contrast to dogs' approximately 15,000-year-old close association with humans, cats probably began to live among humans about 10,000 years ago; they were probably tolerated because of their pest-controlling abilities (Driscoll et al., 2007). Also, in dogs, artificial selection has long been used to develop breeds suitable for roles such as guarding, hunting and herding, whereas cats have not undergone such intensely controlled breeding (Driscoll, Clutton-Brock et al., 2009). Therefore, we set out two competing predictions: 1) If their understanding of human social signals is similar to that of dogs, then cats should also show sensitivity to third-party interactions between humans, expressed as a negative reaction to an anti-social partner; and 2) Due to the weaker influence of selective breeding during domestication, cats should show a lesser capacity for third party-based social evaluation than dogs.

\section{Method}

\section{Subjects}

Thirty-six domestic cats (18 females, 18 males) and their owners participated, recruited through a personal acquaintance network. Thirteen were house cats, and 23 were kept at five cat cafés, where visitors can interact with the resident cats. Two of the cafés housed sheltered feral cats ( 9 cats in total) and the other three housed purebred breeding cats (14 cats). Café cats typically interact with multiple strangers in their daily life. The 'owner' of a cat café was a staff member who usually took care of the cats. We excluded another 11 cats ( 9 from cat cafés, 2 house cats) that failed to complete the sequence of trials due to low motivation (10), or experimenter error (1). Subjects had lived in their café or house for at 
least six months. We set no behavioral criteria for participation: all available individuals were potential participants, and we used all data from those that completed the sequence of trials. The cats were of various breeds, and their ages ranged from 7 months to 14 years. They were randomly divided into two groups of 18, and each participated in one of two conditions: Helper (mean age $=4.13$ years, $S D=3.39$; 10 females, 8 males) or Non-helper (4.43 years, $S D=3.30$; 8 females, 10 males) (see Appendix Table 1). The owners signed a written informed consent before their cats were tested. The cats were not deprived of food or water for the test.

\section{Apparatus and Testing Room}

We visited the owner's house or the cat cafés, all in Kansai or Kanto regions of Japan, and tested each cat individually in a separate room or part of a room. We used a transparent cylindrical container (13 $\mathrm{cm}$ in diameter, $12.5 \mathrm{~cm}$ high), with a lid and an object inside (roll of vinyl tape, diameter $5.5 \mathrm{~cm}$ ). All trials were recorded by two video cameras (Victor GZ-E565-R or SONY HDR-CX390), placed behind, to one side, or in front of the cat, depending on the size and shape of the room.

\section{Procedure}

We showed the cat one of two conditions involving their owner and two female experimenters, an actor and a neutral person (Figure 1). The two experimenters were unfamiliar to the house cats, whereas they were not completely unfamiliar to café cats as they had visited the cafés a few times. The same two people always played roles except for one individual case. Their identities were counterbalanced across participant cats. The actor sat to one side of the owner, and the neutral person sat on the other side. The left-right positions of two experimenters were counterbalanced for the first trial across individuals and across trials. Each cat received four trials with inter-trial intervals of about $60 \mathrm{~s}$. The role of the experimenter was unchanged within the four trials for each cat. The cat, lightly restrained by a third experimenter, about $1 \mathrm{~m}$ from the owner, watched as the owner tried to open the lid of the container. After two or three unsuccessful attempts to open the container (the owner pretended the lid was so tight that $\mathrm{s} /$ he could not pull or twist it open; total duration about $5 \mathrm{~s}$ ), the owner requested help from the actor by holding the container toward her. In the Helper condition, the actor responded by holding the bottom of the container, which facilitated the owner successfully removing the lid and then taking the object out of the container. The owner briefly showed the object to the cat then placed it back in the container and closed the lid. In the Non-helper condition, the actor refused the owner's request for help and instead turned her face away from the owner for 1-2 s. The owner resumed attempting to open the container, but without success. Throughout, the neutral person remained sitting quietly, with no involvement in either condition. Both types of interaction ended with the owner placing the container on the floor in front of her/him. The entire demonstration lasted 10-15 s, which was shorter than in the original dog study (Chijiiwa et al., 2015) because pilot testing revealed that it was harder to maintain the cat's attention for the entire sequence. If the cat did not pay attention to the demonstration, the owner produced a rattling sound by shaking the container or said something like "Can't open," or "Please help," to get the cat's attention. The experimenters said nothing during the demonstration. After the interaction, the actor and the neutral experimenter both placed the cats' favorite food, such as dry, canned, or paste food, on one hand, placed this hand on top of the other hand, and extended both arms to toward the cat to offer the food. If the cat was reluctant to take food offered by hand, the food was offered on a plate $(11 \mathrm{~cm}$ diameter) that was out of view behind the experimenters during the demonstration. The cat was released and allowed to choose one reward. The cat's choice was defined as the first person (actor or neutral person) that the cat approached to sniff, lick, or take the food from. If the cat approached the owner first, the trial continued until it approached either the actor or the neutral person, which was recorded as the cat's 'choice.'

Neither the actor nor the neutral person looked at the cat either during the demonstration or choice phases. The owner looked down at the floor and never made eye contact with the cat during the 
choice phase. The owner was ignorant of the purpose of the experiment. If a cat failed to make a choice within $30 \mathrm{~s}$ on three consecutive trials, we set aside about 10 min during which the cat could behave freely and resumed testing on the next trial. If the cat still did not eat the food, testing was ended.

\section{Figure 1}

Schematic of the Experimental Procedure

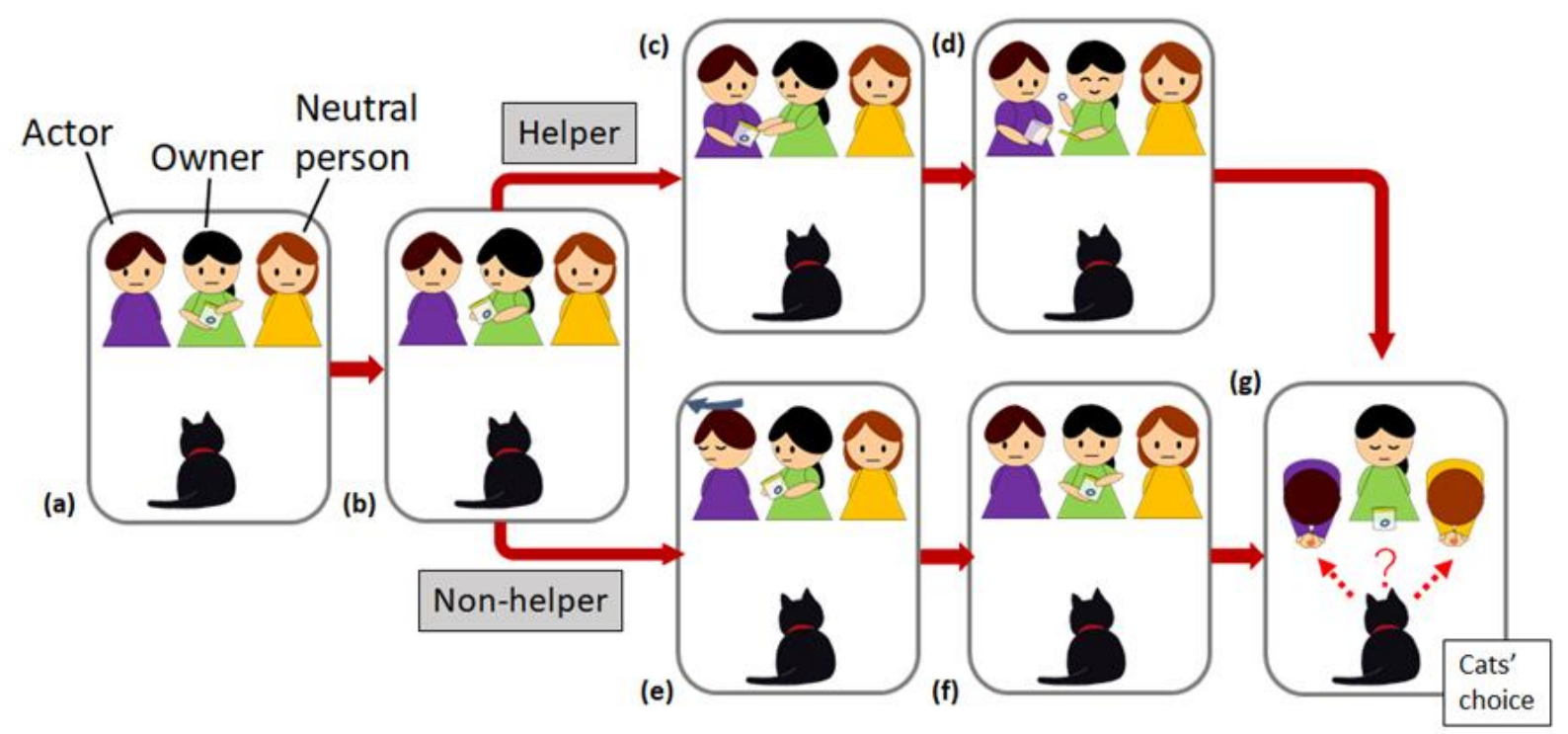

Note. (a) Owner tries unsuccessfully to open the container to remove an object inside. (b) Owner asks Actor for help. (c) In the Helper condition, Actor helps Owner. (d) Owner successfully opens the container and shows the object to the cat. (e) In the Nonhelper condition, Actor refuses to help; turns away. (f) Owner continues trying to open the container but fails. (g) In both conditions, the cats could take food from either Actor or Neutral person.

\section{Results}

Cats received a score of 1 for each choice of the Helper or Non-helper, and a score of 0 for each choice of the neutral person, giving each cat a total score ranging from 0 to 4 . Post-hoc video analyses of $20 \%$ of trials by a second person, blind to the conditions, completely matched the on-site decision. All analyses were conducted with $\mathrm{R}$ version 3.6.1 (R Core Team, 2019).

We used a generalized linear model (GLM) to investigate whether condition, age, sex and home environment affected cats' choices. Condition (Helper/Non-helper), age, sex (female/male) and home environment (café/house) were entered as fixed factors. We applied a binominal distribution to the number of choices for the actor (Helper or Non-helper). To test whether effects were significant, we ran the likelihood ratio test using chi-square (type II tests) in car package (Fox et al., 2012). Figure 2 shows the number of trials in which cats chose the actor in each condition. There was no significant main effect of condition, age, sex or home environment (Table 1).

The number of cats showing a side bias (all choices on the same side) was 6 and 7 in Helper and Non-helper conditions, respectively (Appendix Table 1). After excluding these subjects, we conducted the same analysis as before: there was no significant main effect of condition $\left(\chi^{2}=0.41, p=.52\right)$, age $\left(\chi^{2}=\right.$ $0.75, p=.38)$, sex $\left(\chi^{2}=0.19, p=.66\right)$ or home environment $\left(\chi^{2}=1.14, p=.28\right)$. 
Figure 2

Box Plot of the Number of Choices for the Actor in Each Condition

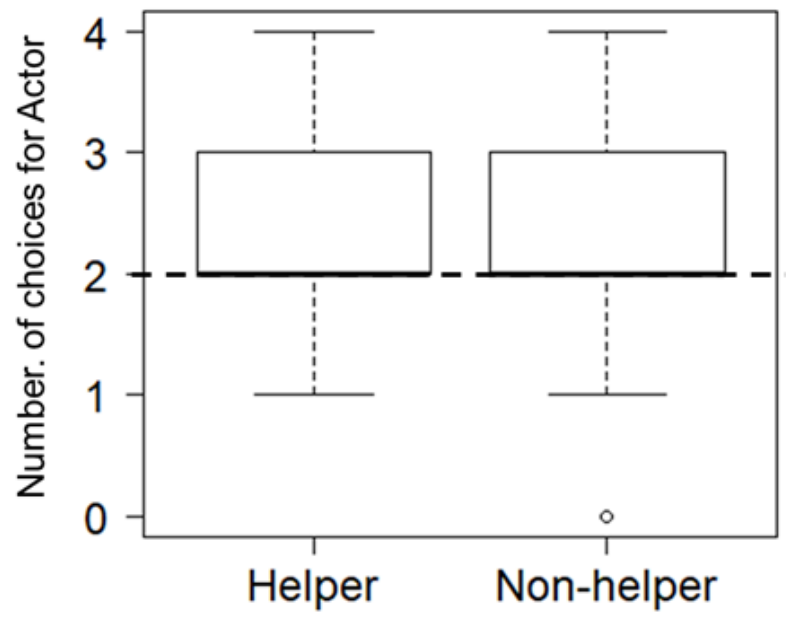

Note. Medians, first and third percentiles, ranges and outliers (dots) are shown. The dashed line shows chance level.

We also analyzed each cat's performance in the first trial, using binomial tests. Nine of 18 cats $(50.0 \%)$ chose the non-neutral actor in the Helper condition and 12 of 18 cats (66.7\%) did so in the Nonhelper condition, neither of which was statistically different from chance level $(p>.99, p=.36$, respectively).

Table 1

Results of the GLM for Effect of Condition (Helper versus Non-helper), cats' age, sex and home environment on the number of choices for the actor

\begin{tabular}{lcccccc}
\hline Term & Estimate & Lower Cl & Upper Cl & $\chi^{2}$ & $d f$ & $p$-value \\
\hline (Intercept) & 0.73 & -0.05 & 1.54 & & & .51 \\
Condition & -0.23 & -0.90 & 0.45 & 0.44 & 1 & .37 \\
Age & 0.00 & -0.01 & 0.00 & 0.80 & 1 & .0 .02 \\
Sex & -0.05 & -0.76 & 0.65 & 1 & .89 \\
Environment & -0.28 & -0.99 & 0.42 & 0.62 & 1 & .43 \\
\hline
\end{tabular}

\section{Discussion}

The aim of this study was to investigate how cats react to third-party interactions involving a person either helping the cats' owner or refusing to help and to compare with studies on monkeys (Anderson et al., 2013) and dogs (Chijiiwa et al., 2015). Negative information is prioritized over positive information in various psychological situations and tasks (for a review: Vaish et al., 2008). Negative agents grab greater attention even if this does not always lead to them being 'avoided' (e.g., Krupenye \& Hare, 2018; Trösch et al., 2020). However, we found no evidence that cats evaluate humans in third-party interactions: they neither avoided a non-helper nor preferred a helper, despite their known sensitivity to 
human behavioral cues. These results support our second prediction: cats' evolved social system and their particular domestication history might have resulted in a restricted capacity for third party-based social evaluation.

As suggested elsewhere (Anderson et al., 2013; Chijiiwa et al., 2015; Hamlin et al., 2010; Vaish et al., 2010), avoidance of antisocial partners can be advantageous when it comes to choosing partners for situations that require cooperative behaviors. The ability to evaluate others from a third-party viewpoint is one of the factors that enable humans to maintain cooperative societies (Nowak, 2006; Wu et al., 2016). One possible reason for domestic cats showing no sign of a negativity bias might be that cooperation is not salient for this species. Whereas dogs are known to cooperate with humans and conspecifics in a variety of real and experimental contexts (Bräuer et al., 2013; Kaminski \& Marshall-Pescini, 2014; Ostojić \& Clayton, 2014), the same is not true of cats. Domestic cats originated from a less gregarious ancestor than did dogs, and they have not been subjected to artificial selection for cooperative work with humans. The capacity for group formation evolved with domestication, leading to the development of an intraspecies social repertoire (Bradshaw \& Cameron-Beaumont, 2000), including establishment of dominance hierarchies (Bradshaw, 2016; Cole \& Shafer, 1966). However, group hunting did not evolve in small cats, because the size of their typical prey items remained unchanged even as cat communities grew bigger (Bradshaw, 2016). Thus, cats can be considered as at least potentially 'social' and flexible in terms of social structure, but without being 'cooperative,' except in the context of cooperative offspring-rearing by females (Bradshaw, 2016; Macdonald et al., 2000). The ability to evaluate others based on indirect experiences might be restricted to more cooperative species. For example, given their cooperation in dayto-day activities including hunting (Stander, 1992) and their ability to solve a cooperative rope-pulling task (Borrego, 2020), lions (also members of the Felidae), might be expected to have this ability.

It is conceivable that the cats in this study did not understand the meaning or goal of the owners' behavior (attempting to open the container to get the object inside). To our knowledge, cats' ability to recognize others' goals or intentions from their actions has not been investigated. But even if they did understand the owner's goal or intention, they might have failed to detect the negative intention of the non-helpful actor (deliberately withholding assistance). Further studies would be valuable for testing alternative third-party evaluation situations and for clarifying whether cats recognize others' goals or intentions.

Finally, we consider that possibility that our experimental situation was simply not appropriate for studying social evaluation by cats. We used an uninteresting object during the demonstration to avoid any evaluation based on foraging opportunities, but this required that the cats maintained attention to human interactions that did not involve food. Compared to dogs, when faced with an unsolvable problem to get food, cats are much less likely to look toward a human for assistance (Miklósi et al., 2005, but see Merola et al., 2015; both species refer to their owner's reactions when presented with a fearful stimulus). Also, Turner (1991) showed that cat-human interactions lasted longer when they were initiated by the cat, which suggests a kind of controlling role for the cats. These results suggest that the human-cat relationship might have some unique features. It is possible that cats would be more interested in different kinds of test situations, for example involving interspecific (human and other cat) interactions as in Leete et al. (2020), or inanimate moving objects.

Importantly, about two thirds of our subjects were from cat cafés, which makes us cautious about generalizing the results of this study to all domestic cats. Recent studies have focused on possible differences in the nature of the bonds with owners in house and café cat populations (Bucher et al., 2020; Saito et al., 2019; Takagi et al., 2019). Although we found no differences between house and café cats, their owner-attachment and socialization histories seem likely to differ. For example, café staff might spend less time interacting with each cat because the greater number of cats in the cafés than in households. Furthermore, compared to house cats, café cats probably interact with more strangers on a daily basis. Future studies are needed to investigate potential effects of attachment level and socialization histories.

Because cats reacted to and used human social cues in face-to-face interactions (Galvan \& Vonk, 2016; Ito et al., 2016; Miklósi et al., 2015; Pongrácz et al., 2018), it seems possible that a first-party 
interaction rather than a third-party one might reveal preference or avoidance in cats. Leete et al. (2020) reported that cats did not show any preference for 'friendly' or 'aggressive' actors based on their direct interaction. However, future work should explore cats' evaluations of humans in more diverse contexts, for example, a 'generous' actor who shared food with them vs. a 'selfish' actor who ate all the food (dogs: Carballo et al., 2015), or a 'nice,' friendly actor over a 'mean,' unresponsive one (dogs: Nitzschner et al., 2012).

It is interesting to relate our findings to 'popular' views about cats as being selfish and less expressive than dogs. Cat-owners have a lower tendency than dog-owners to regard their pets as 'family members,' and their cats were scored significantly lower on traits including 'friendly,' 'sympathetic,' and 'compassionate' (Arahori et al., 2017). However, cat owners who did regard their cats as family members tended to attribute more compassion to their pets. Another questionnaire study found that owners did consider their cats as family members capable of understanding human emotional and communicative signals, as well as empathy (Pongrácz \& Szapu, 2018). Both anthropomorphism and societal biases influence owners' views of psychological (including emotional) capacities and their pets' relationship with owners (O'Farrell, 1997; Pongrácz \& Szapu, 2018), as well as the latters' behavior (Shreve \& Udell, 2015). Further empirical research comparing the socio-cognitive abilities of cats and dogs might contribute positively toward improving overall pet-human relationships.

\section{Acknowledgements}

This work was financially supported by JSPS KAKENHI Grant Number No. 16J08691 to Hitomi Chijiiwa, No. 17J08974 to Saho Takagi, No. 16J1034 to Minori Arahori, and Nos. 16H06301, 16H01505, 16H01726, 15K12047, 26119514, 25240020, and 25118002 to Kazuo Fujita from the Japan Society for the Promotion of Science (JSPS). We wish to thank Atsuko Saito, Mana Tsuzuki, Ayami Hyuga, Benoit Bucher and Zsofia Budai for their assistance in conducting experiments. We also thank all cats and their owners for their participation.

\section{References}

Abdai, J., \& Miklósi, Á. (2016). The origin of social evaluation, social eavesdropping, reputation formation, image scoring or what you will. Frontiers in Psychology, 7, 1772. https://doi.org/10.3389/fpsyg.2016.01772

Anderson, J. R., Bucher, B., Chijiiwa, H., Kuroshima, H., Takimoto, A., \& Fujita, K. (2017). Third-party social evaluations of humans by monkeys and dogs. Neuroscience \& Biobehavioral Reviews, 82, 95-109. https://doi.org/10.1016/j.neubiorev.2017.01.003

Anderson, J. R., Kuroshima, H., Takimoto, A., \& Fujita, K. (2013). Third-party social evaluation of humans by monkeys. Nature Communications, 4, 1-5. https://doi.org/10.1038/ncomms2495

Arahori, M., Kuroshima, H., Hori, Y., Takagi, S., Chijiiwa, H., \& Fujita, K. (2017). Owners' view of their pets' emotions, intellect, and mutual relationship: Cats and dogs compared. Behavioural Processes, 141, 316321. https://doi.org/10.1016/J.BEPROC.2017.02.007

Baumeister, R. F., Bratslavsky, E., Finkenauer, C., \& Vohs, K. D. (2001). Bad is stronger than good. Review of General Psychology, 5, 323-370. https://doi.org/10.1037//1089-2680.5.4.323

Borrego, N. (2020). Socially tolerant lions (Panthera leo) solve a novel cooperative problem. Animal Cognition, 23, 327-336. https://doi.org/10.1007/s10071-019-01336-4

Bradshaw, J. W. (2016). Sociality in cats: A comparative review. Journal of Veterinary Behavior, 11, 113-124. https://doi.org/10.1016/j.jveb.2015.09.004

Bradshaw, J. W. S., \& Cameron-Beaumont, C. (2000). The signalling repertoire of the domestic cat and its undomesticated relatives. In D. C. Turner \& P. Bateson (Eds.), The domestic cat: The biology of its behaviour (pp. 67-193). Cambridge University Press.

Bräuer, J., Bös, M., Call, J., \& Tomasello, M. (2013). Domestic dogs (Canis familiaris) coordinate their actions in a problem-solving task. Animal Cognition, 16, 273-285. https://doi.org/10.1007/s10071-012-0571-1

Bshary, R. (2002). Biting cleaner fish use altruism to deceive image-scoring client reef fish. Proceedings of the Royal Society of London. Series B: Biological Sciences, 269, 2087-2093. https://doi.org/10.1098/rspb. 2002.2084 
Bucher, B., Arahori, M., Chijiiwa, H., Takagi, S., \& Fujita, K. (2020). Domestic cats' reactions to their owner and an unknown individual petting a potential rival. Pet Behaviour Science, 9, 16-33. https://doi.org/10.21071/pbs.vi9.12176

Carballo, F., Freidin, E., Putrino, N., Shimabukuro, C., Casanave, E., \& Bentosela, M. (2015). Dog's discrimination of human selfish and generous attitudes: The role of individual recognition, experience, and experimenters' gender. PLoS ONE, 10: e0116314. https://doi.org/10.1371/journal.pone.0116314

Caro, T. M., Fitzgibbon, C. D., \& Holt, M. E. (1989). Physiological costs of behavioural strategies for male cheetahs. Animal Behaviour, 38, 309-317. https://doi.org/10.1016/S0003-3472(89)80092-2

Chijiiwa, H., Kuroshima, H., Hori, Y., Anderson, J. R., \& Fujita, K. (2015). Dogs avoid people who behave negatively to their owner: Third-party affective evaluation. Animal Behaviour, 106, 123-127. https://doi.org/10.1016/j.anbehav.2015.05.018

Cole, D. D., \& Shafer, J. N. (1966). A study of social dominance in cats. Behaviour, 27, 39-52.

Driscoll, C. A., Clutton-Brock, J., Kitchener, A. C., \& O’Brien, S. J. (2009). The taming of the cat. Genetic and archaeological findings hint that wildcats became housecats earlier--and in a different place--than previously thought. Scientific American, 300, 68-75.

Driscoll, C. A., Macdonald, D. W., \& O’Brien, S. J. (2009). From wild animals to domestic pets, an evolutionary view of domestication. Proceedings of the National Academy of Sciences, 106, 9971-9978. https://doi.org/10.1073/pnas.0901586106

Driscoll, C. A., Menotti-Raymond, M., Roca, A. L., Hupe, K., Johnson, W. E., Geffen, E., Harley, E. H., Delibes, M., Pontier, D., Kitchener, A. C., Yamaguchi, N., O’Brien, S. J., \& Macdonald, D. W. (2007). The Near Eastern origin of cat domestication. Science, 317, 519-523. https://doi.org/10.1126/science.1139518

Edwards, C., Heiblum, M., Tejeda, A., \& Galindo, F. (2007). Experimental evaluation of attachment behaviors in owned cats. Journal of Veterinary Behavior, 2, 119-125. https://doi.org/10.1016/j.jveb.2007.06.004

Fox, J., Weisberg, S., Adler, D., Bates, D., Baud-Bovy, G., Ellison, S., \& Heiberger, R. (2012) Package 'car'. R Foundation for Statistical Computing, Vienna

Galvan, M., \& Vonk, J. (2016). Man's other best friend: Domestic cats (F. silvestris catus) and their discrimination of human emotion cues. Animal Cognition, 19, 193-205. https://doi.org/10.1007/s10071-015-0927-4

Hamlin, J. K. (2013). Moral judgment and action in preverbal infants and toddlers: Evidence for an innate moral core. Current Directions in Psychological Science, $\quad 22, \quad 186-193$. https://doi.org/10.1177/0963721412470687

Hamlin, J. K., \& Wynn, K. (2011). Young infants prefer prosocial to antisocial others. Cognitive Development, 26, 30-39. https://doi.org/10.1016/j.cogdev.2010.09.001

Hamlin, J. K., Wynn, K., \& Bloom, P. (2007). Social evaluation by preverbal infants. Nature, 450, 557-559. https://doi.org/10.1203/PDR.0b013e318168c6e5

Hamlin, J. K., Wynn, K., \& Bloom, P. (2010). Three-month-olds show a negativity bias in their social evaluations. Developmental Science, 13, 923-929. https://doi.org/10.1111/j.1467-7687.2010.00951.x

Herrmann, E., Keupp, S., Hare, B., Vaish, A., \& Tomasello, M. (2013). Direct and indirect reputation formation in nonhuman great apes (Pan paniscus, Pan troglodytes, Gorilla gorilla, Pongo pygmaeus) and human children (Homo sapiens). Journal of Comparative Psychology, 127, 63-75. https://doi.org/10.1037/a0028929

Ito, Y., Watanabe, A., Takagi, S., Arahori, M., \& Saito, A. (2016). Cats beg for food from the human who looks at and calls to them: Ability to understand humans' attentional states. Psychologia, 59, 112-120. https://doi.org/10.2117/psysoc.2016.112.

Johnson, C. M., Sullivan, J., Jensen, J., Buck, C., Trexel, J., \& St. Leger, J. (2018). Prosocial predictions by bottlenose dolphins (Tursiops spp.) based on motion patterns in visual stimuli. Psychological Science, 29, 1405-1413. https://doi.org/10.1177/0956797618771078

Kaminski, J., \& Marshall-Pescini, S. (2014). The social dog: Behavior and cognition. Academic Press.

Kawai, N., Yasue, M., Banno, T., \& Ichinohe, N. (2014). Marmoset monkeys evaluate third-party reciprocity. Biology Letters, 10, 20140058. https://doi.org/10.1098/rsbl.2014.0058

Krupenye, C., \& Hare, B. (2018). Bonobos prefer individuals that hinder others over those that help. Current Biology, 28, 280-286. https://doi.org/10.1016/j.cub.2017.11.061

Kundey, S. M. A., de Los Reyes, A., Royer, E., Molina, S., Monnier, B., German, R., \& Coshun, A. (2011). Reputation-like inference in domestic dogs (Canis familiaris). Animal Cognition, 14, $291-302$. https://doi.org/10.1007/s10071-010-0362-5

Leete, J., Vonk, J., Oriani, S., Eaton, T., \& Lieb, J. (2020). Do domestic cats (Felis silvestris catus) infer reputation in humans after direct and indirect experience? Human-Animal Interaction Bulletin, 8, 35-53. 
Macdonald, D. W., Yamaguchi, N., \& Kerby, G. (2000). Group-living in the domestic cat: Its sociobiology and epidemiology. In D. C. Turner \& P. Bateson (Eds.), The domestic cat: The biology of its behaviour (pp. 95118). Cambridge University Press.

Marshall-Pescini, S., Passalacqua, C., Ferrario, A., Valsecchi, P., \& Prato-Previde, E. (2011). Social eavesdropping in the domestic dog. Animal Behaviour, 81, 1177-1183. https://doi.org/10.1016/j.anbehav.2011.02.029

McAuliffe, K., Bogese, M., Chang, L. W., Andrews, C. E., Mayer, T., Faranda, A., Hamlin, J.K., \& Santos, L. R. (2019). Do dogs prefer helpers in an infant-based social evaluation task? Frontiers in Psychology, $10,591$. https://doi.org/10.3389/fpsyg.2019.00591

Merola, I., Lazzaroni, M., Marshall-Pescini, S., \& Prato-Previde, E. (2015). Social referencing and cat-human communication. Animal Cognition, 18, 639-648. https://doi.org/10.1007/s10071-014-0832-2

Miklósi, A., Pongrácz, P., Lakatos, G., Topál, J., \& Csányi, V. (2005). A comparative study of the use of visual communicative signals in interactions between dogs (Canis familiaris) and humans and cats (Felis catus) and humans. Journal of Comparative Psychology, 119, 179-186. https://doi.org/10.1037/07357036.119.2.179

Nitzschner, M., Melis, A. P., Kaminski, J., \& Tomasello, M. (2012). Dogs (Canis familiaris) evaluate humans on the basis of direct experiences only. PLoS One, 7, e46880. https://doi.org/10.1371/journal.pone.0046880

Nowak, M. A. (2006). Five rules for the evolution of cooperation. Science, 314, 1560-1563. https://doi.org/10.1126/science.1133755

O'Farrell, V. (1997). Owner attitudes and dog behaviour problems. Applied Animal Behaviour Science, 52, $205-213$. https://doi.org/10.1016/S0168-1591(96)01123-9

Ostojić, L., \& Clayton, N. S. (2014). Behavioural coordination of dogs in a cooperative problem-solving task with a conspecific and a human partner. Animal Cognition, 17, 445-459. https://doi.org/10.1007/s10071-0130676-1

Pongrácz, P., \& Onofer, D. L. (2020). Cats show an unexpected pattern of response to human ostensive cues in a series of A-not-B error tests. Animal Cognition, 23, 681-689. https://doi.org/10.1007/s10071-020-01373-4

Pongrácz, P., \& Szapu, J. S. (2018). The socio-cognitive relationship between cats and humans - Companion cats (Felis catus) as their owners see them. Applied Animal Behaviour Science, 207, 57-66. https://doi.org/10.1016/j.applanim.2018.07.004

Pongrácz, P., Szapu, J. S., \& Faragó, T. (2018). Cats (Felis silvestris catus) read human gaze for referential information. Intelligence, 74, 43-52. https://doi.org/10.1016/j.intell.2018.11.001

Quaranta, A., d'Ingeo, S., Amoruso, R., \& Siniscalchi, M. (2020). Emotion recognition in cats. Animals, $10,1107$. https://doi.org/10.3390/ani10071107

R Core Team (2019). R: A language and environment for statistical computing [Computer software]. R Foundation for Statistical Computing. https://www.R-project.org/.

Rozin, P., \& Royzman, E. B. (2001). Negativity bias, negativity dominance, and contagion. Personality and Social Psychology Review, 5, 296-320. https://doi.org/10.1207/S15327957PSPR0504_2

Russell, Y. I., Call, J., \& Dunbar, R. I. (2008). Image scoring in great apes. Behavioural Processes, 78, $108-111$. https://doi.org/10.1016/j.beproc.2007.10.009

Saito, A., \& Shinozuka, K. (2013). Vocal recognition of owners by domestic cats (Felis catus). Animal Cognition, 16, 685-90. https://doi.org/10.1007/s10071-013-0620-4

Saito, A., Shinozuka, K., Ito, Y., \& Hasegawa, T. (2019). Domestic cats (Felis catus) discriminate their names from other words. Scientific Reports, 9, 1-8. https://doi.org/10.1038/s41598-019-40616-4

Shreve, K. R. V., \& Udell, M. A. R. (2015). What's inside your cat's head? A review of cat (Felis silvestris catus) cognition research past, present and future. Animal Cognition, 18, 1195-1206. https://doi.org/10.1007/s10071-015-0897-6

Stander, P. E. (1992). Cooperative hunting in lions: The role of the individual. Behavioral Ecology and Sociobiology, 29, 445-454. https://www.jstor.org/stable/4600646

Subiaul, F., Vonk, J., Okamoto-Barth, S., \& Barth, J. (2008). Do chimpanzees learn reputation by observation? Evidence from direct and indirect experience with generous and selfish strangers. Animal Cognition, 11, 611-623. https://doi.org/10.1007/s10071-008-0151-6

Takagi, S., Arahori, M., Chijiiwa, H., Saito, A., Kuroshima, H., \& Fujita, K. (2019). Cats match voice and face: Cross-modal representation of humans in cats (Felis catus). Animal Cognition, 22, 901-906. https://doi.org/10.1007/s10071-019-01265-2

Trösch, M., Pellon, S., Cuzol, F., Parias, C., Nowak, R., Calandreau, L., \& Lansade, L. (2020). Horses feel emotions when they watch positive and negative horse-human interactions in a video and transpose what they saw to real life. Animal Cognition, 23, 643-653. https://doi.org/10.1007/s10071-020-01369-0 
Turner, D. C. (1991). The ethology of the human-cat relationship. Schweizer Archiv fur Tierheilkunde, 133, 63-70. https://doi.org/10.5169/seals-588724

Vaish, A., Carpenter, M., \& Tomasello, M. (2010). Young children selectively avoid helping people with harmful intentions. Child Development, 81, 1661-1669. https://doi.org/10.1111/j.1467-8624.2010.01500.x

Vaish, A., Grossmann, T., \& Woodward, A. (2008). Not all emotions are created equal: The negativity bias in social-emotional development. Psychological Bulletin, 134, 383-403. https://doi.org/10.1037/00332909.134.3.383

Vitale, K. R., Behnke, A. C., \& Udell, M. A. R. (2019). Attachment bonds between domestic cats and humans. Current Biology, 29, R864-R865. https://doi.org/10.1016/j.cub.2019.08.036

Vitale, K. R., \& Udell, M. A. R. (2019). The quality of being sociable: The influence of human attentional state, population, and human familiarity on domestic cat sociability. Behavioural Processes, 158, 11-17. https://doi.org/10.1016/j.beproc.2018.10.026

Wu, J., Balliet, D., \& Van Lange, P. A. (2016). Reputation, gossip, and human cooperation. Social and Personality Psychology Compass, 10, 350-364. https://doi.org/10.1111/spc3.12255 


\section{Appendix Table 1}

Subject cats and total choice for the actor (helper or non-helper) in each of the four trials

\section{Helper Condition}

\begin{tabular}{|c|c|c|c|c|c|c|c|c|c|c|}
\hline \multirow{2}{*}{ Breed } & \multirow{2}{*}{ Sex $* 1$} & \multirow{2}{*}{$\begin{array}{l}\text { Age } \\
\text { (years:months) }\end{array}$} & \multirow{2}{*}{ Home environment } & \multicolumn{4}{|c|}{ Trial $* 2$} & \multirow{2}{*}{ Total } & & \multirow{2}{*}{ Side $* 3$} \\
\hline & & & & 1 & 2 & 3 & 4 & & & \\
\hline American Shorthair & $\mathrm{F}$ & 3:02 & house & 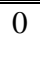 & 1 & 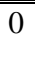 & 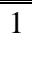 & & 2 & LLLL \\
\hline American Shorthair & M & $11: 09$ & house & 0 & 1 & 0 & 0 & & 1 & RRRL \\
\hline Mongrel & $\mathrm{F}$ & 2:07 & house & 0 & 1 & 1 & 0 & & 2 & LLRR \\
\hline Mongrel & M & 5:04 & café & 1 & 1 & 1 & 1 & & 4 & LRLR \\
\hline Mongrel & M & 1:02 & café & 0 & 1 & 1 & 1 & & 3 & RRLR \\
\hline Mongrel & $\mathrm{F}$ & 2:04 & café & 1 & 1 & 1 & 1 & & 4 & RLRL \\
\hline Mongrel & M & 0:07 & café & 0 & 1 & 1 & 1 & & 3 & LLRL \\
\hline Mongrel & $\mathrm{F}$ & $1: 02$ & café & 1 & 0 & 0 & 1 & & 2 & LLRR \\
\hline Mongrel & $\mathrm{F}$ & $2: 10$ & house & 0 & 1 & 1 & 1 & & 3 & RRLR \\
\hline Mongrel & M & 1:07 & house & 0 & 0 & 1 & 1 & & 2 & LRRL \\
\hline Mongrel & M & 7:07 & house & 0 & 1 & 0 & 1 & & 2 & RRRR \\
\hline Mongrel & M & 5:00 & house & 1 & 1 & 0 & 0 & & 2 & LRRL \\
\hline Munchkin & $\mathrm{F}$ & $1: 10$ & café & 1 & 1 & 0 & 1 & & 3 & RLLL \\
\hline Munchkin & M & 1:09 & café & 1 & 0 & 1 & 0 & & 2 & LLLL \\
\hline Munchkin & $\mathrm{F}$ & 3:08 & café & 1 & 0 & 1 & 0 & & 2 & LLLL \\
\hline Munchkin & $\mathrm{F}$ & $7: 11$ & café & 1 & 0 & 0 & 1 & & 2 & RRLL \\
\hline Persian & $\mathrm{F}$ & $11: 11$ & café & 1 & 0 & 1 & 0 & & 2 & LLLL \\
\hline Skookum & $\mathrm{F}$ & $2: 03$ & café & 0 & 1 & 0 & 1 & & 2 & LLLL \\
\hline Average/median & & 4.13 & & & & & & & 2 & \\
\hline
\end{tabular}

Non-helper Condition

\begin{tabular}{|c|c|c|c|c|c|c|c|c|c|c|}
\hline \multirow[b]{2}{*}{ Breed } & \multirow[b]{2}{*}{ Sex } & \multirow{2}{*}{$\begin{array}{l}\text { Age } \\
\text { (years:months) }\end{array}$} & \multirow[b]{2}{*}{ Home environment } & \multicolumn{4}{|c|}{ Trial } & \multirow{2}{*}{\multicolumn{2}{|c|}{ Total }} & \multirow[b]{2}{*}{ Side } \\
\hline & & & & 1 & 2 & 3 & 4 & & & \\
\hline American Shorthair & M & $3: 07$ & café & 0 & 0 & 1 & 1 & & 2 & LRRL \\
\hline American Shorthair & M & $2: 01$ & café & 1 & 1 & 0 & 1 & & 3 & RLRR \\
\hline American Shorthair & $\mathrm{F}$ & $5: 02$ & café & 1 & 1 & 1 & 0 & & 3 & RLRR \\
\hline American Shorthair & $\mathrm{F}$ & 4:00 & café & 1 & 0 & 1 & 0 & & 2 & LLLL \\
\hline Mongrel & $\mathrm{F}$ & 4:05 & house & 1 & 0 & 1 & 0 & & 2 & LLLL \\
\hline Mongrel & $\mathrm{M}$ & $1: 03$ & café & 1 & 0 & 0 & 0 & & 1 & RRLR \\
\hline Mongrel & $\mathrm{F}$ & $7: 06$ & café & 0 & 1 & 0 & 1 & & 2 & LLLL \\
\hline
\end{tabular}


Chijiiwa et al. 35

\begin{tabular}{|c|c|c|c|c|c|c|c|c|c|}
\hline Mongrel & M & 7:06 & café & 1 & 1 & 1 & 0 & 3 & LRLL \\
\hline Mongrel & M & 3:06 & café & 1 & 0 & 1 & 0 & 2 & LLLL \\
\hline Mongrel & M & $2: 10$ & house & 0 & 1 & 0 & 1 & 2 & RRRR \\
\hline Mongrel & $\mathrm{F}$ & $14: 03$ & house & 1 & 0 & 0 & 0 & 1 & LLRL \\
\hline Mongrel & $\mathrm{F}$ & $5: 08$ & house & 0 & 0 & 1 & 0 & 1 & LRRR \\
\hline Mongrel & M & 0:07 & café & 0 & 1 & 0 & 1 & 2 & RRRR \\
\hline Mongrel & M & $0: 11$ & house & 1 & 0 & 1 & 1 & 3 & LLLR \\
\hline Mongrel & M & $1: 11$ & house & 1 & 1 & 1 & 1 & 4 & LRLR \\
\hline Norwegian Forest Cat & M & $0: 11$ & café & 0 & 0 & 0 & 0 & 0 & LRLR \\
\hline Scottish Fold & $\mathrm{F}$ & $7: 08$ & café & 1 & 1 & 1 & 1 & 4 & RLRL \\
\hline Scottish Fold & $\mathrm{F}$ & $6: 00$ & café & 1 & 0 & 1 & 0 & 2 & RRRR \\
\hline Average/median & & 4.43 & & & & & & 2 & \\
\hline
\end{tabular}

${ }^{* 1} \mathrm{M}$ : male; F: female.

*20: choice for the neutral person; 1 : choice for the actor (helper or non-helper).

${ }^{*} \mathrm{~L}$ : left; $\mathrm{R}$ : right, from the cat's point of view. 